Check for updates

Cite this: RSC Adv., 2021, 11, 9285

Received 3rd February 2021

Accepted 24th February 2021

DOI: $10.1039 / \mathrm{d} 1 \mathrm{ra00922b}$

rsc.li/rsc-advances

\section{Synthesis and evaluation of modified siRNA molecules containing a novel glucose derivative $\uparrow$}

\author{
Lidya Salim, ${ }^{a}$ Eva Goss ${ }^{b}$ and Jean-Paul Desaulniers (D) *a \\ Chemical modifications are critical for the development of safe and effective siRNAs for downstream \\ applications. In this study, we report the synthesis of a novel glucose phosphoramidite, a triazole-linked \\ to uracil at position one, for incorporation into oligonucleotides. Biological testing revealed that the \\ glucose derivative at key positions within the sense or antisense strand can lead to potent gene-silencing \\ activity, thus highlighting its tolerance in both sense and antisense positions. Furthermore, the A-form \\ helical formation was maintained with this modification. Overall, placing the modification at the $3^{\prime}$ end \\ and at key internal positions led to effective RNAi gene-silencing activity.
}

\section{Introduction}

RNA interference (RNAi) is a natural mechanism that mediates sequence-specific gene silencing by targeting messenger RNA and suppressing translation. ${ }^{1}$ This pathway involves the assembly of an RNA-induced silencing complex (RISC) which incorporates double-stranded RNA sequences called short interfering RNAs (siRNAs). ${ }^{2}$ Each siRNA duplex is $\sim 21$ nucleotides in length and is made up of a guide (antisense) strand and a passenger (sense) strand. After the siRNA duplex is unwound by RISC, the passenger strand is removed by the endonuclease Argonaute2 (Ago2), while the guide strand is retained and used as a guide sequence to locate and cleave the mRNA target. $^{3}$ Synthetic siRNAs are compatible with the endogenous RNAi pathway and are able to reduce the expression of target proteins, serving not only as experimental tools but also as gene-silencing therapeutics. Despite recent advances in the field, such as the U.S. FDA approval of three RNAi-based therapies, ${ }^{4,5}$ the development of safe and effective siRNA therapeutics has been limited by the inherent structure of RNA which poses challenges like low stability, poor cellular uptake, and offtarget effects. ${ }^{6,7}$

Chemical modifications can be used to optimize the pharmacokinetic properties of siRNAs for in vivo applications. Several modifications have been developed to date, including backbone, nucleobase, and sugar modifications, which can be incorporated individually or in combination..$^{8-10}$ Nevertheless, there is still no universal modification that mitigates all the aforementioned challenges, so there is great interest in

${ }^{a}$ University of Ontario Institute of Technology, Faculty of Science, 2000 Simcoe Street North, Oshawa, ON L1G 0C5, Canada.E-mail: jean-paul.desaulniers@ontariotechu. $\mathrm{ca}$

${ }^{b}$ Synthose Inc., 50 Viceroy Road Unit 7, Concord, ON L4K 3A7, Canada

† Electronic supplementary information (ESI) available. See DOI: 10.1039/d1ra00922b designing and investigating novel modifications that could be incorporated in for future siRNA design.

Modifications of the ribose sugar have been extensively studied to improve stability and siRNA potency. The presence of the $2^{\prime}$ hydroxyl group makes RNA more susceptible to hydrolysis and is often modified, as it is not required for RNAi activity. ${ }^{11}$ Common $2^{\prime}$ modifications include $2^{\prime}$-fluoro and $2^{\prime}$-methoxy, which increase siRNA stability. ${ }^{12}$ Other modifications include bicyclic derivatives like locked nucleic acids (LNA), which lock the ribose sugar in the $\mathrm{C}_{3}^{\prime}$-endo conformation, ${ }^{13}$ and acyclic derivatives like unlocked nucleic acids (UNA), which lack the $\mathrm{C}_{2}^{\prime}-\mathrm{C}_{3}^{\prime}$-bond of the ribose sugar. ${ }^{14}$

A more recent approach involves replacing the ribose sugar with six-carbon moieties. Altritol nucleic acids have displayed stronger activity than unmodified siRNAs, particularly when placed at the $3^{\prime}$ end of the sense or antisense strand..$^{15}$ Cyclohexenyl and hexitol nucleic acids have also shown increased activity as well as nuclease stability. ${ }^{16,17}$ Herein, we explore the synthesis of a novel glucose phosphoramidite derivative, which is a triazole-linked to a uracil nucleobase at position one. This modification was introduced at either terminal or internal positions of the sense or antisense strand, resulting in siRNA duplexes containing a single $3^{\prime}-6^{\prime} / 2^{\prime}-5^{\prime}$ phosphodiester linkage.

\section{Experimental}

\section{Chemicals and general methods}

$\beta$-D-Glucopyranosyl azide was obtained from Synthose, Inc. Canada. Other starting reagents and solvents were obtained from other commercial sources such as Sigma Aldrich and used without further purification, unless otherwise stated. Standard flash chromatography was performed using Silicycle Siliaflash 60 (230-400 mesh). ${ }^{1} \mathrm{H},{ }^{13} \mathrm{C}$ and ${ }^{31} \mathrm{P}$ NMRs were recorded in $\mathrm{CDCl}_{3}$ or $\mathrm{CD}_{3} \mathrm{OD}$ using a Bruker Avance III NMR spectrometer. NMR spectra are provided in the ESI Data. $\dagger$ 


\section{Compound 1}

To a solution of $\beta$-D-glucopyranosyl azide $(0.5 \mathrm{~g}, 2.44 \mathrm{mmol})$ in anhydrous pyridine $(7 \mathrm{~mL})$ at $0{ }^{\circ} \mathrm{C}$ was added 1,3 -dichloro1,1,3,3-tetraisopropyldisiloxane (1.1 eq., $2.68 \mathrm{mmol}, 0.86 \mathrm{~mL}$ ). The mixture was allowed to equilibrate to room temperature and was stirred under argon for 6 hours. The reaction was quenched with methanol and concentrated in vacuo. The crude product was taken up in ethyl acetate and washed with water and sodium bicarbonate. The organic layer was dried over sodium sulphate, concentrated in vacuo and purified using flash chromatography (3:7 ethyl acetate $/ n$-hexanes) to yield compound 1 as a white solid $(0.677 \mathrm{~g}, 62 \%) .{ }^{1} \mathrm{H}$ NMR $(400 \mathrm{MHz}$, $\left.\mathrm{CDCl}_{3}\right) . \delta 4.59(\mathrm{~d}, 1 \mathrm{H}), 4.10(\mathrm{dd}, 1 \mathrm{H}), 4.00(\mathrm{dd}, 1 \mathrm{H}), 3.82(\mathrm{t}, 1 \mathrm{H})$, $3.6(\mathrm{t}, 1 \mathrm{H}), 3.33-3.28(\mathrm{~m}, 2 \mathrm{H}), 1.11-1.02(\mathrm{~m}, 28 \mathrm{H}) .{ }^{13} \mathrm{C}$ NMR (101 $\left.\mathrm{MHz} \mathrm{CDCl}_{3}\right) . \delta 90.8,78.7,76.5,73.4,68.8,60.6,17.4,17.3,17.2$, $17.1,13.6,13.2,12.5$.

\section{Compound 2}

To a solution of compound $1(0.45 \mathrm{~g}, 1 \mathrm{mmol})$ in DMF $(5.5 \mathrm{~mL})$ was added $p$-toluenesulfonic acid monohydrate (0.2 eq., $0.2 \mathrm{mmol}, 0.038 \mathrm{~g}$ ). The mixture was stirred at room temperature under argon. After 6.5 hours, the reaction mixture was diluted with ethyl acetate and washed with water and sodium bicarbonate. The organic layer was dried over sodium sulphate, concentrated in vacuo and purified using flash chromatography (3: 7 ethyl acetate $/ n$-hexanes) to yield compound 2 as a white solid (0.248 g, 55\%). ${ }^{1} \mathrm{H}$ NMR (400 MHz, $\left.\mathrm{CDCl}_{3}\right) . \delta 4.62$ (d, 1H), 3.95 (dd, $1 \mathrm{H}), 3.78$ (dd, 1H), 3.73-3.66 (m, 2H), 3.48-3.44 (m, 1H), $3.39(\mathrm{t}, 1 \mathrm{H}), 2.62(\mathrm{~d}, 1 \mathrm{H}), 1.12-1.02(\mathrm{~m}, 28 \mathrm{H}) .{ }^{13} \mathrm{C}$ NMR $(101 \mathrm{MHz}$, $\left.\mathrm{CDCl}_{3}\right) . \delta 89.6,79.8,78.4,73.8,72.1,61.9,17.2,12.9,12.8,12.1$.

\section{Compound 3}

To a solution of compound $2(0.6 \mathrm{~g}, 1.34 \mathrm{mmol})$ in anhydrous pyridine $(3 \mathrm{~mL})$ was added anhydrous trimethylamine $(0.56 \mathrm{~mL}$, $4 \mathrm{mmol}$ ) under argon. While stirring the reaction at $0{ }^{\circ} \mathrm{C}, 4,4^{\prime}$ dimethoxytrityl chloride ( 1.5 eq., $2 \mathrm{mmol}, 0.681 \mathrm{~g}$ ) was added in 5 equal portions over a 5 hour period. The reaction mixture was allowed to equilibrate to room temperature and was stirred for an additional 7 hours. The solvent was removed in vacuo and the crude product was taken up in dichloromethane and washed with sodium bicarbonate. The organic layer was dried over sodium sulphate, concentrated in vacuo and purified using flash chromatography (3:7 ethyl acetate/n-hexane) to yield compound 3 as a yellow oil $(0.75 \mathrm{~g}, 75 \%) .{ }^{1} \mathrm{H}$ NMR $(400 \mathrm{MHz}$, $\mathrm{CDCl}_{3}$ ). $\delta$ 7.22-7.08 (m, 9H), 6.75-6.73 (m, 4H), $4.5(\mathrm{~d}, 1 \mathrm{H}), 3.85$ (ddd, $1 \mathrm{H}), 3.7$ (s, 6H), 3.7-3.64 (m, 1H), 3.61-3.58 (m, 1H), 3.383.34 (m, 1H), 3.31-3.27 (td, 1H), 2.6 (d, 1H), 1.03-0.93 (m, 28H). ${ }^{13} \mathrm{C}$ NMR (101 MHz, $\mathrm{CDCl}_{3}$ ). $\delta$ 158.6, 147.3, 139.5, 129.1, 127.8, 127.1, 113.6, 113.2, 112.6, 89.6, 79.8, 73.9, 72.1, 61.9, 60.4, 17.2, 12.8, 12.1 .

\section{Compound 4}

To a mixture of compound $3(0.25 \mathrm{~g}, 0.33 \mathrm{mmol})$ and propargyl uracil $(0.055 \mathrm{~g}, 0.37 \mathrm{mmol})$ in anhydrous acetonitrile $(5 \mathrm{~mL})$ was added copper(I) iodide $(0.007 \mathrm{~g}, 0.036 \mathrm{mmol})$ under argon. The solution was stirred at room temperature for 6 hours. The solvent was removed in vacuo and the crude product was purified using flash chromatography (gradient: $0 \%$ to $5 \%$ methanol/ dichloromethane) to yield compound 4 as an off-yellow foam (0.23 g, 77\%). ${ }^{1} \mathrm{H}$ NMR (400 MHz, $\left.\mathrm{CD}_{3} \mathrm{OD}\right) . \delta 9.10$ (s, 1H), 7.52 (d, $1 \mathrm{H}), 7.46(\mathrm{~d}, 1 \mathrm{H}), 7.36-7.31(\mathrm{~m}, 5 \mathrm{H}), 7.25-7.19(\mathrm{~m}, 4 \mathrm{H}), 7.10(\mathrm{~d}$, $1 \mathrm{H}), 6.87-6.84(\mathrm{~m}, 4 \mathrm{H}), 5.73-5.64(\mathrm{~m}, 1 \mathrm{H}), 5.0(\mathrm{~s}, 1 \mathrm{H}), 4.10(\mathrm{t}$, $1 \mathrm{H}), 3.97-3.87$ (m, 2H), 3.72-3.63 (m, 2H), 3.57 (d, 1H), 2.8 (brs, 1H), 1.33-1.03 (m, 28H). ${ }^{13} \mathrm{C}$ NMR (101 MHz, $\left.\mathrm{CDCl}_{3}\right) . \delta$ 158.6, 158.4 , 147.3, 144.9, 139.5, 130.1, 129.1, 127.9, 127.8, 127.1, 113.6, 113.2, 102.8, 87.26, 86.44, 81.4, 79.9, 72.9, 71.9, 61.6, 51.9, 29.7, 17.3, 12.8, 12.1. ESI-HRMS (ES + ) $m / z$ calculated for $\mathrm{C}_{46} \mathrm{H}_{61} \mathrm{~N}_{5} \mathrm{O}_{10} \mathrm{Si}_{2}+\mathrm{H}^{+}$: 900.3957, found 900.4038 [M+ $\left.\mathrm{H}^{+}\right]$.

\section{Compound 5}

To a flame-dried round-bottomed flask was added a solution of compound $4(0.25 \mathrm{~g}, 0.29 \mathrm{mmol})$ in anhydrous dichloromethane ( $4 \mathrm{~mL}$ ), followed by the addition of anhydrous triethylamine (0.14 mL, $1.4 \mathrm{mmol}$ ) under an argon atmosphere. 2-Cyanoethyl$N, N$-diisopropylchlorophosphoramidite $(0.19 \mathrm{~mL}, 0.833 \mathrm{mmol})$ was then added drop-wise and the reaction was stirred at room temperature for 1.5 hours. Due to stability concerns, the crude product was purified using a short flash chromatography column (gradient: $20 \%$ to $70 \%$ ethyl acetate $/ n$-hexane, maintaining $5 \%$ triethylamine) to yield compound 5 as a yellow oil (0.26 g, 84\%), which was immediately used for solid-phase oligonucleotide synthesis. ${ }^{31} \mathrm{P}$ NMR (162 $\left.\mathrm{MHz}, \mathrm{CDCl}_{3}\right) . \delta \mathrm{ppm}$ 147.83, 147.79.

\section{Oligonucleotide synthesis}

Oligonucleotides were synthesized on an Applied Biosystems 394 DNA/RNA synthesizer using $1.0 \mu \mathrm{M}$ controlled-pore glass (CPG) support columns and a $1.0 \mu \mathrm{M}$ cycle with a 999 second coupling time. Phosphoramidites were resuspended in anhydrous acetonitrile, immediately before use, to a final concentration of $0.1 \mathrm{M}$. Oligonucleotide cleavage from the solid support columns was achieved by flushing the CPG columns with $1 \mathrm{~mL}$ EMAM solution (1:1 methylamine $33 \mathrm{wt} \%$ in ethanol/methylamine $40 \mathrm{wt} \%$ in water) for 1 hour at room temperature, followed by overnight incubation in EMAM to deprotect the bases. Oligonucleotides were concentrated in a MiVac Quattro Concentrator and later resuspended in DMSO $(100 \mu \mathrm{M})$. The silyl protecting groups were removed by incubating the oligonucleotides with $3 \mathrm{HF}-\mathrm{Et}_{3} \mathrm{~N}(125$ $\mu \mathrm{L}$ ) for 3 hours at $65^{\circ} \mathrm{C}$. Crude oligonucleotides were precipitated in ethanol and desalted using Millipore Ampicon Ultra $3000 \mathrm{MW}$ cellulose centrifugal filters. Strands were purified using reversephase HPLC eluting from $5 \%$ to $95 \%$ ACN in 0.1 M TEAA buffer (pH 7.0).

\section{Thermal denaturation and circular dichroism (CD) studies}

For duplex formation, equimolar amounts of the respective sense and antisense strands were combined, dried down and resuspended in $400 \mu \mathrm{L}$ sodium phosphate buffer $(90 \mathrm{mM} \mathrm{NaCl}$, $10 \mathrm{mM} \mathrm{Na}_{2} \mathrm{HPO}_{4}, 1 \mathrm{mM}$ EDTA; pH 7.0). Samples were heated for 2 minutes at $90{ }^{\circ} \mathrm{C}$ and allowed to slowly equilibrate to room temperature. Thermal denaturation and CD studies were 
performed using a Jasco J-815 CD Spectropolarimeter equipped with a temperature controller. To determine the melting temperature $\left(T_{\mathrm{m}}\right)$ of each duplex, the change in absorbance at $260 \mathrm{~nm}$ was measured against a temperature gradient from 15 to $95{ }^{\circ} \mathrm{C}$, at $0.5^{\circ} \mathrm{C} \mathrm{min}^{-1}$. Data were analysed using Meltwin v3.5 software. CD spectra were recorded at $25^{\circ} \mathrm{C}$, scanning from 200 to $40 \mathrm{~nm}$ with a screening rate of $20.0 \mathrm{~nm} \mathrm{~min}{ }^{-1}$ and a $0.20 \mathrm{~nm}$ data pitch. Scans were performed in triplicate and averaged using Jasco's Spectra Manager v2 software.

\section{Biological assays}

Cell culture and transfection. HeLa cells were maintained in Dulbecco's Modified Eagle's Medium (DMEM) supplemented with $10 \%$ fetal bovine serum (FBS) and $1 \%$ penicillinstreptomycin (Sigma). Cells were maintained at $37{ }^{\circ} \mathrm{C}$ in a humidified atmosphere with $5 \% \mathrm{CO}_{2}$ and were passaged at $80 \%$ confluency. HeLa cells were seeded into 24-well plates, containing $400 \mu \mathrm{L} \mathrm{DMEM} \mathrm{(10 \%} \mathrm{FBS),} \mathrm{at} \mathrm{a} \mathrm{density} \mathrm{of} 5.0 \times 10^{4}$ cells per well. Cells were incubated for 24 hours at $37{ }^{\circ} \mathrm{C}$ in a humidified atmosphere with $5 \% \mathrm{CO}_{2}$ after which the culture medium was removed. For each transfection sample, a mixture of $1 \mu \mathrm{L}$ Lipofectamine $2000^{\mathrm{TM}}$ (Invitrogen) and $49 \mu \mathrm{L} 1 \mathrm{X}$ Gibco's Opti-MEM Reduced Serum Medium (Invitrogen) was incubated at room temperature for $5 \mathrm{~min}$. Each siRNA was diluted in $1 \mathrm{X}$ Gibco's Opti-MEM Reduced Serum Medium on ice and mixed with $200 \mathrm{ng}$ pGL3 and $50 \mathrm{ng}$ pRLSV40 plasmids to achieve a final volume of $50 \mu \mathrm{L}$. The siRNA-plasmid mix was added to the Lipofectamine $2000^{\mathrm{TM}}$ Opti-MEM mix and incubated for 40 minutes at room temperature. These samples were then transferred to the respective wells of the 24-well plate and incubated for 24 hours at $37^{\circ} \mathrm{C}$ prior to cell lysis.

Dual-Luciferase ${ }^{\circledR}$ Reporter Assay. Cells were lysed with $1 \times$ passive lysis buffer for $30 \mathrm{~min}$ at room temperature. Cell lysates $(10 \mu \mathrm{L})$ were transferred to opaque Costar 96-well plates in triplicate for the Dual-Luciferase ${ }^{\circledR}$ Reporter Assay (Promega). Luciferase Assay Reagent II (LAR II) and Stop \& Glo® Reagent were prepared following the manufacturer's protocol. LAR II (50 $\mu \mathrm{L}$ ) was added to each well and luminescence was immediately measured using a Synergy HT (Bio-Tek) plate luminometer. Stop \& Glo® $(50 \mu \mathrm{L})$ was then added to each well and a second luminescence measurement was taken. Results are expressed as the ratio of firefly/Renilla luminescence taken as a percentage of an untreated control.

\section{Results and discussion}

\section{Preparation of oligonucleotides}

To synthesize the glucose phosphoramidite $\mathbf{5}$, we first treated $\beta$ D-glucopyranosyl azide with TIPDSCl $\mathrm{T}_{2}$. This was followed by the acid-catalyzed migration of the 4,6-TIPDS protecting group to yield the 3,4-protected derivative 2 , as previously reported in the literature. ${ }^{18}$ This compound was protected with $4,4^{\prime}$-dimethoxytrityl (DMT) and then reacted with N1-propargyl uracil via copper(I)-catalyzed azide-alkyne cycloaddition (CuAAC). The resulting compound $\mathbf{4}$ was phosphitylated with 2-cyanoethyl$N, N$-diisopropylchlorophosphoramidite to yield the phosphoramidite derivative 5 (Scheme 1), which was used for solid-phase oligonucleotide synthesis as described above. The modification was incorporated at key positions within the sense or antisense strand, replacing either the $3^{\prime} \mathrm{dTdT}$ overhang or an internal uridine nucleotide. Oligonucleotides strands were purified using reverse-phase HPLC (ESI Fig. S1†) and characterized by mass spectrometry (ESI Table S1†).

\section{CD studies}

Modified sense and antisense strands were annealed to their complementary wild-type sequences. The resulting duplexes were characterized using circular dichroism spectroscopy as described above to confirm that siRNAs adopted an A-form helical conformation. Recognition of the A-form major groove by RISC is required for proper RNAi activity, so this is an important criterion in siRNA design. ${ }^{19}$ An A-form helical structure is characterized by a broad positive band at $260 \mathrm{~nm}$ in addition to a negative band at $\sim 210 \mathrm{~nm} .{ }^{20}$ As seen in Fig. 1, our



Scheme 1 Synthesis of a glucose nucleoside containing a triazole-linked uracil base, and its phosphoramidite derivative. Reagents and conditions: (i) $\mathrm{TIPDSCl}_{2}$, pyridine, $0^{\circ} \mathrm{C} \rightarrow \mathrm{rt}, 6 \mathrm{~h}\left(62 \%\right.$ ), (ii) $\mathrm{p}-\mathrm{TsOH} \cdot \mathrm{H}_{2} \mathrm{O}, \mathrm{DMF}, \mathrm{RT}, 6.5 \mathrm{~h}(55 \%)$, (iii) DMT- $\mathrm{Cl}, \mathrm{Et}{ }_{3} \mathrm{~N} / \mathrm{pyridine}, 0{ }^{\circ} \mathrm{C}, 5 \mathrm{~h}, 0{ }^{\circ} \mathrm{C} \rightarrow \mathrm{rt}, 7 \mathrm{~h}$ (75\%), (iv) N1-propargyl uracil, Cul, ACN, rt, 6 h (77\%), (v) 2-cyanoethyl-N,N-diisopropylchlorophosphoramidite, Et ${ }_{3} \mathrm{~N} / \mathrm{DCM}, \mathrm{rt}, 1.5 \mathrm{~h}(84 \%)$. 


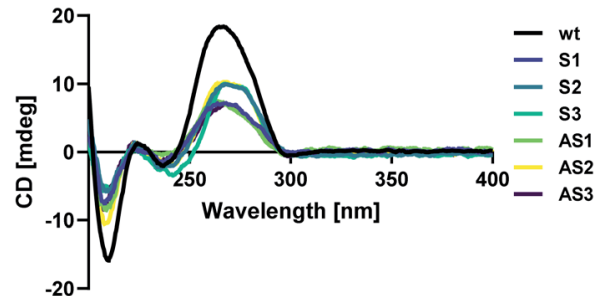

Fig. 1 Circular dichroism (CD) spectra of anti-luciferase siRNAs.

modification did not distort the A-form helical structure of the siRNA duplex, regardless of its placement in the sequence.

\section{Thermal denaturation}

Since the thermodynamic properties of siRNAs have been shown to impact siRNA potency, we assessed the thermal stability of each duplex. The resulting melting temperatures $\left(T_{\mathrm{m}}\right)$ are indicated in Table 1 . Placing our modification at the $3^{\prime}$ end of the sense or antisense strand, replacing the dTdT overhang, had a small impact on thermal stability with $\Delta T_{\mathrm{m}}$ values of $-5{ }^{\circ} \mathrm{C}$. This could be due to the loss of stacking interactions which have been reported with $3^{\prime} \mathrm{dTdT}$ overhangs. ${ }^{21}$ Internal modifications resulted in strong thermal destabilization.

Placing the modification at positions 12 or 16 from the sense strand $5^{\prime}$ end resulted in $\Delta T_{\mathrm{m}}$ values of $-22{ }^{\circ} \mathrm{C}$ and $-26{ }^{\circ} \mathrm{C}$, respectively. Similar effects were observed when placing the modification at positions 10 and 16 from the antisense strand $5^{\prime}$ end, with $\Delta T_{\mathrm{m}}$ values of $-22.5{ }^{\circ} \mathrm{C}$ and $-17{ }^{\circ} \mathrm{C}$, respectively. These results were expected as the internal region of siRNA is far less tolerant to bulky chemical modifications than the $3^{\prime}$ end. ${ }^{22}$

\section{Gene-silencing activity}

To assess the gene-silencing activity of siRNAs, HeLa cells were co-transfected with plasmids coding for firefly and Renilla luciferases as well as siRNAs, using Lipofectamine $2000^{\mathrm{TM}}$ (Invitrogen). We then used the Dual-Luciferase® Reporter Assay to evaluate the relative expression of target firefly luciferase after

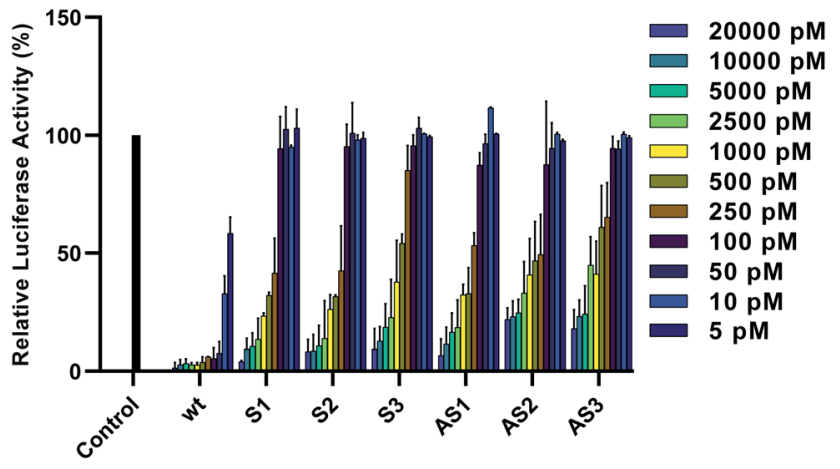

Fig. 2 Relative expression of normalized firefly luciferase in HeLa cells 24 hours after siRNA treatment. Error bars indicate standard deviation of at least two independent biological replicates.

siRNA treatments ranging from 5 to 20000 pM. As seen in Fig. 2, all tested siRNAs showed dose-dependent knockdown of firefly luciferase after 24 hours. IC $_{50}$ values are summarized in Table 1. Duplexes bearing terminal modifications, placed at the $3^{\prime}$ end of the sense or antisense strand, showed high genesilencing activity with $\mathrm{IC}_{50}$ values of $218 \mathrm{pM}$ and $226 \mathrm{pM}$, respectively. This is consistent with literature reports showing that six-carbon sugar derivatives are well-tolerated and can lead to strong gene-silencing activity when placed at the $3^{\prime}$ end of the siRNA sense or antisense strand. Although internal modifications were tolerated in both the sense and the antisense strand, their effect on siRNA activity was position dependent. Placing our modification at position 16 from the sense or antisense strand $5^{\prime}$ end led to efficient gene-silencing activity $\left(\mathrm{IC}_{50}\right.$ of 219 pM), comparable to our terminal-modified siRNAs. On the other hand, placing our modification at position 10 from the antisense strand $5^{\prime}$ end led to a decrease in gene-silencing activity $\left(\mathrm{IC}_{50}\right.$ of $\left.483 \mathrm{pM}\right)$. It has been reported that the seed region, which directs the initial target recognition by RISC, is more sensitive to chemical modifications, particularly if they disrupt the thermal stability of the duplex. ${ }^{22}$ The lowest activity,

Table 1 Sequences, melting temperatures and $I_{50}$ values of anti-firefly luciferase siRNAs ${ }^{a}$

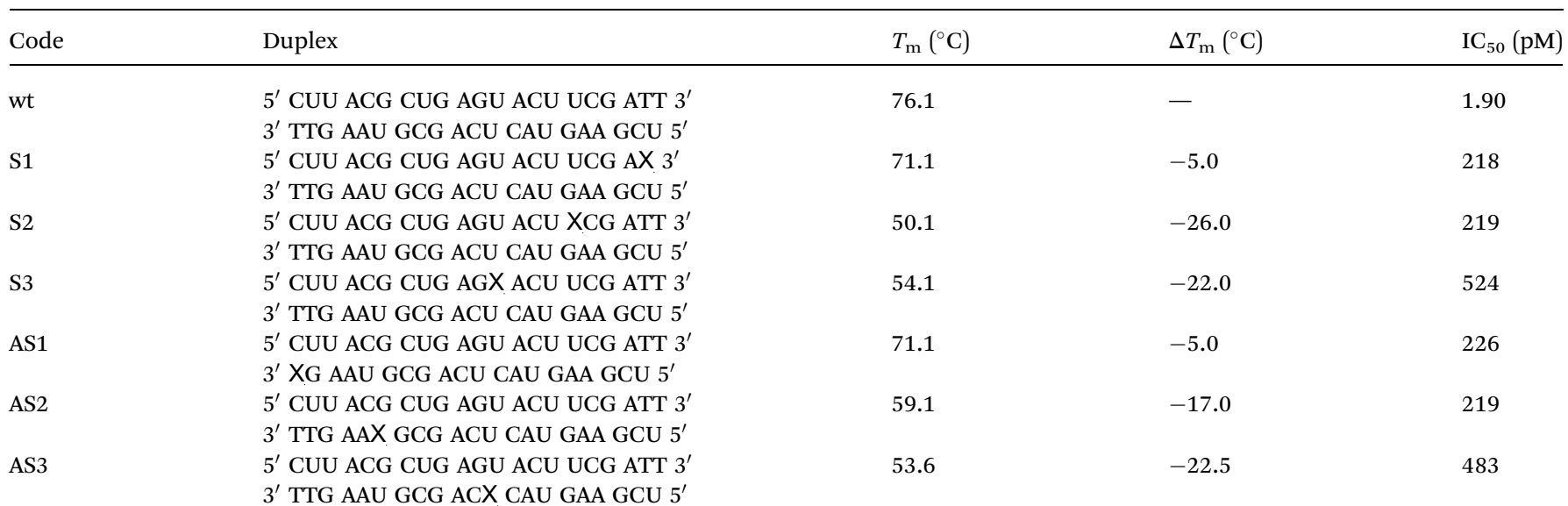

${ }^{a}$ The top strand corresponds to the sense strand. The bottom strand corresponds to the antisense strand. $\underline{\mathrm{X}}$ corresponds to the triazole-linked uracil modification. Inhibitory dose-response curves can be found in the ESI Data (ESI Fig. S2). 
however, was observed with siRNA S3, bearing the modification at position 12 from the sense strand $5^{\prime}$ end $\left(\mathrm{IC}_{50}\right.$ of $\left.524 \mathrm{pM}\right)$.

Some reports suggest that this position can be less tolerant to chemical modifications, including altritol nucleic acids. ${ }^{23}$ Given the proximity to the Ago2 cleavage site, it has been proposed that some chemical modifications at this position can interfere with the enzymatic activity of Ago2 thus compromising siRNA potency. ${ }^{24}$ Based on these data, this modification may be better suited for incorporation at the $3^{\prime}$ end of the sense or antisense strand as well as at some internal in order to maximize gene-silencing activity.

\section{Conclusion}

In summary, we report the synthesis of a novel glucose phosphoramidite with a triazole-linked uracil moiety at position 1 for incorporation into oligonucleotides using standard solid-phase synthetic conditions. This modification was placed at terminal and internal positions of the siRNA sense or antisense strand to investigate its biophysical and biological effects. Overall, this modification was well-tolerated within the sense and the antisense strand and did not distort the A-form helical conformation of the siRNAs, making it suitable for RNAi applications. Notably, our modified siRNAs show position-dependent gene-silencing activity. Replacing the dT overhang at the $3^{\prime}$ end or modifying position 16 from the $5^{\prime}$ end of either stand resulted in high siRNA activity. This position-dependent effect could be further investigated to optimize siRNA potency. Although there are some general guidelines for siRNA design, these criteria are not universally applicable, highlighting the importance of assessing the effect of each chemical modification individually. To the best of our knowledge, this is the first report of an siRNA bearing a single $3^{\prime}-6^{\prime} / 2^{\prime}-5^{\prime}$ phosphodiester linkage.

\section{Author contributions}

Lidya Salim: data curation; investigation; methodology; visualization; writing - original draft. Eva Goss: funding acquisition; project administration; resources. Jean-Paul Desaulniers: conceptualization; funding acquisition; project administration; resources; supervision; writing - review \& editing.

\section{Conflicts of interest}

There are no conflicts to declare.

\section{Acknowledgements}

We acknowledge the Natural Sciences and Engineering Research Council (NSERC) for funding. We also acknowledge Ifrodet Giorgees for assistance with mass spectrometry analysis.

\section{Notes and references}

1 N. Agrawal, P. V. Dasaradhi, A. Mohmmed, P. Malhotra, R. K. Bhatnagar and S. K. Mukherjee, Microbiol. Mol. Biol. Rev., 2003, 67, 657-685.
2 G. J. Hannon, Nature, 2002, 418, 244-251.

3 S. M. Elbashir, J. Harborth, W. Lendeckel, A. Yalcin, K. Weber and T. Tuschl, Nature, 2001, 411, 494-498.

4 D. Adams, A. Gonzalez-Duarte, W. D. O'Riordan, C. C. Yang, M. Ueda, A. V. Kristen, I. Tournev, H. H. Schmidt, T. Coelho, J. L. Berk, K. P. Lin, G. Vita, S. Attarian, V. Planté-Bordeneuve, M. M. Mezei, J. M. Campistol, J. Buades, T. H. Brannagan III, B. J. Kim, J. Oh, Y. Parman, Y. Sekijima, P. N. Hawkins, S. D. Solomon, M. Polydefkis, P. J. Dyck, P. J. Gandhi, S. Goyal, J. Chen, A. L. Strahs, S. V. Nochur, M. T. Sweetser, P. P. Garg, A. K. Vaishnaw, J. A. Gollob and O. B. Suhr, N. Engl. J. Med., 2018, 379, 11-21.

5 L. J. Scott, Drugs, 2020, 80, 335-339.

6 L. Aagaard and J. J. Rossi, Adv. Drug Delivery Rev., 2007, 59, 75-86.

7 D. Haussecker, J. Controlled Release, 2014, 195, 49-54.

8 C. Selvam, D. Mutisya, S. Prakash, K. Ranganna and R. Thilagavathi, Chem. Biol. Drug Des., 2017, 90, 665-678.

9 J. K. Watts, G. F. Deleavey and M. J. Damha, Drug Discovery Today, 2008, 13, 842-855.

10 D. A. Braasch, S. Jensen, Y. Liu, K. Kaur, K. Arar, M. A. White and D. R. Corey, Biochemistry, 2003, 42, 7967-7975.

11 Y.-L. Chiu and T. M. Rana, RNA, 2003, 9, 1034-1048.

12 D. M. Kenski, G. Butora, A. T. Willingham, A. J. Cooper, W. Fu, N. Qi, F. Soriano, I. W. Davies and W. M. Flanagan, Mol. Ther.-Nucleic Acids, 2012, 1, e5.

13 J. Elmén, H. Thonberg, K. Ljungberg, M. Frieden, M. Westergaard, Y. Xu, B. Wahren, Z. Liang, H. Ørum, T. Koch and C. Wahlestedt, Nucleic Acids Res., 2005, 33, 439-447.

14 P. Nielsen, L. H. Dreiøe and J. Wengel, Bioorg. Med. Chem., 1995, 3, 19-28.

15 M. Fisher, M. Abramov, A. Van Aerschot, D. Xu, R. L. Juliano and P. Herdewijn, Nucleic Acids Res., 2007, 35, 1064-1074.

16 K. Nauwelaerts, M. Fisher, M. Froeyen, E. Lescrinier, A. Van Aerschot, D. Xu, R. DeLong, H. Kang, R. L. Juliano and P. Herdewijn, J. Am. Chem. Soc., 2007, 129, 9340-9348.

17 M. Fisher, M. Abramov, A. Van Aerschot, J. Rozenski, V. Dixit, R. L. Juliano and P. Herdewijn, Eur. J. Pharmacol., 2009, 606, 38-44.

18 M. Farrell, J. Zhou and P. V. Murphy, Chem. -Eur. J., 2013, 19, 14836-14851.

19 A. R. Hernández, L. W. Peterson and E. T. Kool, ACS Chem. Biol., 2012, 7, 1454-1461.

20 J. Kypr, I. Kejnovská, D. Renciuk and M. Vorlícková, Nucleic Acids Res., 2009, 37, 1713-1725.

21 A. S. O'Toole, S. Miller and M. J. Serra, RNA, 2005, 11, 512516.

22 J. Bramsen and J. Kjems, Front. Genet., 2012, 3, 1-22.

23 P. Kumar, R. Degaonkar, D. C. Guenther, M. Abramov, G. Schepers, M. Capobianco, Y. Jiang, J. Harp, C. Kaittanis, M. M. Janas, A. Castoreno, I. Zlatev, M. K. Schlegel, P. Herdewijn, M. Egli and M. Manoharan, Nucleic Acids Res., 2020, 48, 4028-4040.

24 J. Zheng, L. Zhang, J. Zhang, X. Wang, K. Ye, Z. Xi, Q. Du and Z. Liang, FASEB J., 2013, 27, 4017-4026. 